\title{
MASSIVE DEEP VEIN THROMBOSIS AND PULMONARY EMBOLISM IN THE COURSE OF MAY-THURNER SYNDROME - NEW HYBRID VENOUS STENT IMPLANTATION AFTER SUCCESSFUL DIRECT THROMBOLYSIS COMPLICATED WITH LATE EXTRAPERITONEAL BLEEDING
}

\author{
Bartłomiej Janiak1, Ireneusz Babiak1, Jacek Czyczerski' , Agata Romanowska1', \\ Dariusz Janczak ${ }^{2,3}$ \\ 'Department of Cardiology, Intensive Cardiology Care and Angiology, Regional Speciality \\ Hospital "Latawiec", Swidnica, Poland \\ 2Surgical Clinic, IV Military Hospital, Wroclaw, Poland \\ ${ }^{3}$ Surgical Specialities Facility, Medical University of Wroclaw, Poland
}

\author{
CASE REPORT \\ Phlebological Review 2015; 23, 3: 86-91 \\ DOI: $10.5114 /$ pr.2015.57469
}

Submitted: 6.11 .2015

Accepted: 24.11 .2015

\begin{abstract}
We present a case of a 37-year-old patient with progressing deep vein thrombosis of the left lower limb, affecting the femoral and iliac veins, and also the distal part of the inferior vena cava, which was accompanied by pulmonary embolism. Endovascular treatment consisted of implantation of a retrievable vena cava filter and catheter-directed thrombolysis of the veins of the lower extremity. Thrombolytic treatment that lasted $72 \mathrm{~h}$ resulted in almost complete restoration of patency of thrombosed veins. Still, since intravascular ultrasound revealed a compression of the left iliac vein (May-Thurner syndrome) the treatment was completed by implantation of the new-generation hybrid venous stent: Sinus-Obliquus (Optimed, Ettlingen, Germany). After 3 weeks the caval filter was removed and the patient returned to normal everyday activity.
\end{abstract}

Key words: deep venous thrombosis, iliac vein compression syndrome, vena cava filter, venous stenting, direct thrombolysis.

\section{ADDRESS FOR CORRESPONDENCE}

Bartłomiej Janiak

Department of Cardiology,

Intensive Cardiology Care and Angiology, Regional Speciality Hospital „Latawiec”, Leśna 27-29, 58-100 Świdnica, Poland e-mail: bmjaniak@poczta.onet.pl

\section{INTRODUCTION}

According to European data, acute deep vein thrombosis (DVT) affects approximately 1 in 1000 adults per year [1]. Assuming that the present population of Poland is approximately 38 million citizens, it is estimated that about 38,000 people per year will suffer from this disabling and potentially life-threatening disease. It is estimated that despite an early and following-the-guidelines treatment for DVT, $45 \%$ of these patients $(17,100$ individuals) within 2 years after the first event will develop post-thrombotic syndrome. According to many studies, approximately $10 \%$ of DVT patients will suffer from the next thrombotic event within the next 2 years [2]. Catheter-directed thrombolytic therapy, which is recommended by many current guidelines and recommendations, still remains an underused treatment modality. This problem especially concerns younger patients (20-40 years old) suffering from left-sided DVT, since in these patients more than $50 \%$ of thrombotic events are related to a potentially manageable factor, such as compression of the left iliac vein by the right iliac artery (known as May-Thurner or Cockett's syndrome) $[3,4]$. In these patients a successful thrombolytic therapy combined with implantation of a venous stent can result in a very good long-term clinical outcome, and these patients can return to work and their normal everyday activities $[4,5]$.

\section{CASE REPORT}

The 37-year-old female patient with obesity [102 kg; body mass index (BMI): 37.9 ), hyperlipidaemia and glucose intolerance, with 18-day history of left lower leg DVT manifesting with persistent and severe oedema, was admitted to the hospital due to dyspnoea. Because of DVT this patient was previously admitted to another hospital and discharged with the recommendation of anticoagulation with rivaroxaban $15 \mathrm{mg}$ twice a day.

Potential risk factors of thrombosis in this case comprised oral contraceptives taken during the last 3 months before the event. Mild anaemia (haemoglobin: $10.2 \mathrm{~g} / \mathrm{dl}$ ) was the only laboratory abnormality revealed on admission. Clinical probability of pulmonary embolism (PE) rated by both the Wells criteria and the Revised Gene- 
va Score was intermediate. Echocardiography assessment did not detect right ventricle enlargement or other secondary signs of right ventricle overload. The left ventricular ejection fraction was approximately $60 \%$. Computed tomography (CT) angiography of the veins of lower extremities and pelvis, which was performed on the day of admission, revealed radiographic signs of thrombosis (dilatation of the vein with lack of enhancement of its lumen) of the left femoral vein, pelvic veins and the inferior vena cava up to the level of L3-L4 (Fig. 1). Therefore, we also performed CT angiography of the pulmonary arteries. This study detected the signs of $\mathrm{PE}$ in the lobular, segmental and subsegmental arteries. Based on the clinical status of the patient and the Pulmonary Embolism Severity Index (PESI) we estimated the probability of early 30-day mortality as low and considered our patient as low-risk according to the PESI score [6], which meant that according to current guidelines PE should be managed conservatively.

After discontinuation of rivaroxaban and 48-hour intravenous infusion of heparin, the Option ELITE retrievable vena cava filter (Argon Medical Devices, Plano, TX, USA) was temporarily implanted into the inferior vena cava via the right jugular vein (Fig. 2). Then, after cannulation under ultrasound guidance of the left

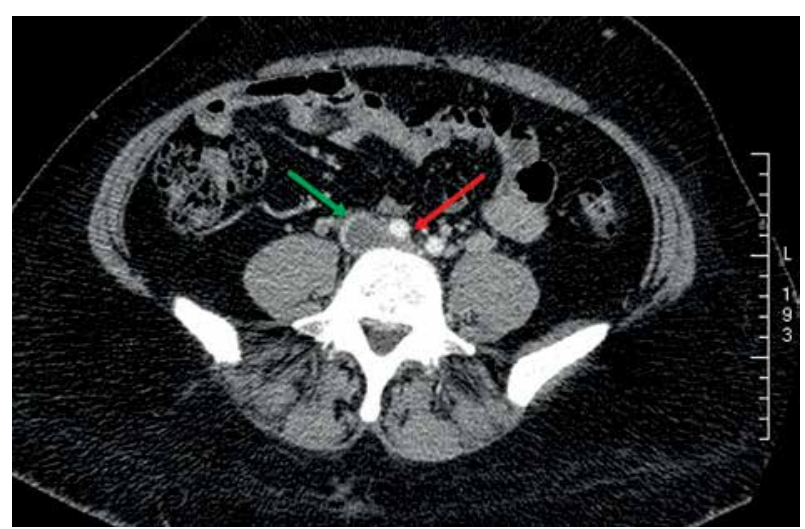

Fig. 1. Compression of the left common iliac vein by the right common iliac artery (red arrow) revealed by angio-CT. Propagation of the thrombus to the contralateral common iliac vein (green arrow)

popliteal vein, a standard $6 \mathrm{~F} 11 \mathrm{~cm}$ long catheter sheath was inserted over the 0.035 " guidewire. Under fluoroscopic guidance, we navigated through the obstruction of femoral and iliac veins using a short loop made of the 0.035 " $260 \mathrm{~cm}$ long stiff-type Terumo hydrophilic guidewire (Terumo Corp., Tokyo, Japan), which was supported

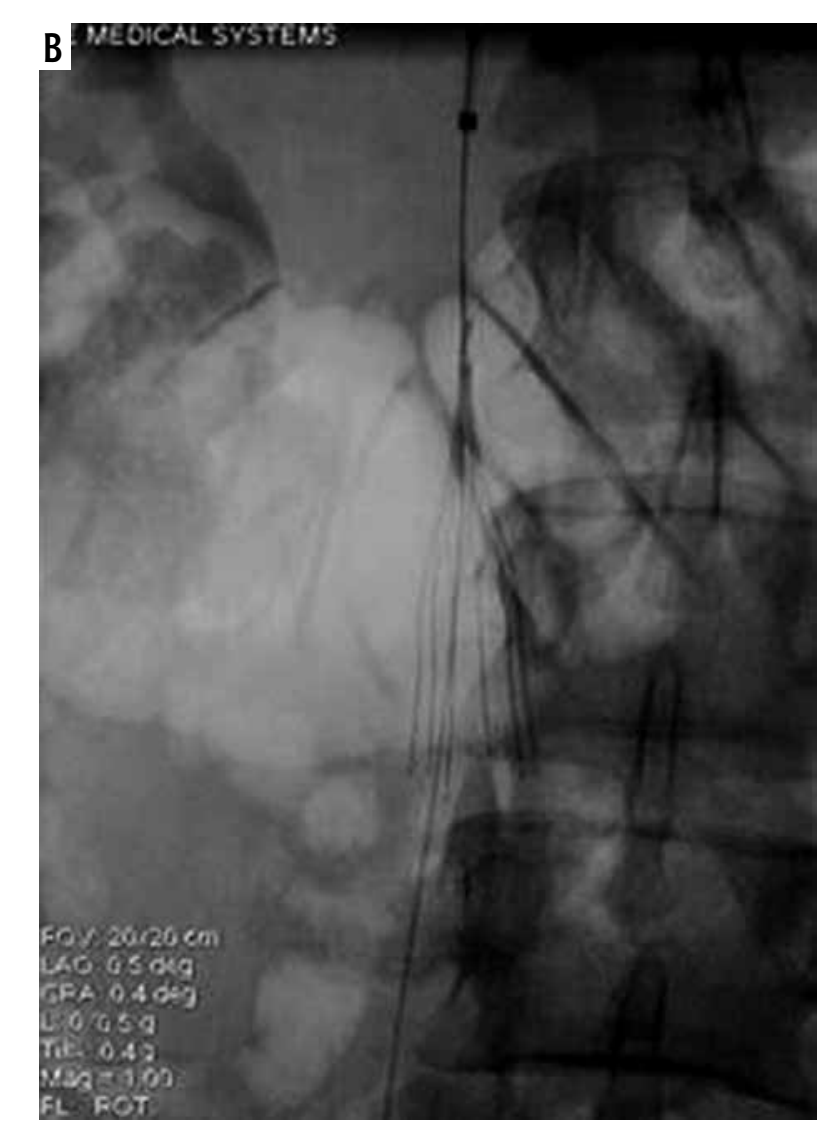

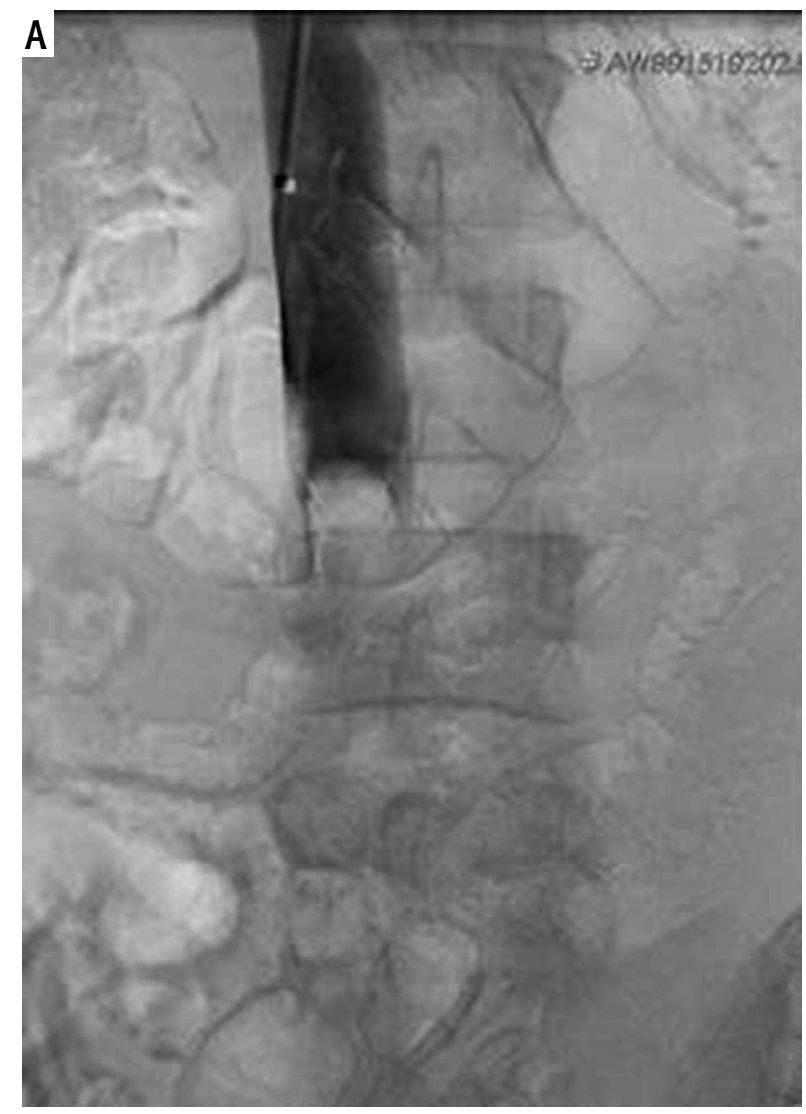

Fig. 2. Extension of the thrombus into the inferior vena cava demonstrated by venography performed through the $6 \mathrm{~F}$ sheath introduced from the right external jugular vein for filter placement (A). The retrievable vena cava filter implanted below the level of renal veins (B) 
by the $4 \mathrm{~F}$ vertebral hydrophilic catheter (Cook Medical Inc., Bloomington, IN, USA). The crossing was relatively easy, except for the proximal part of the left common iliac vein, where some force was needed to enter the inferior vena cava. Then, over the guidewire we introduced the $4 \mathrm{~F}$ Fountain thrombolysis catheter (Merit Medical Systems Inc., South Jordan, UT, USA) with the working length of the system $50 \mathrm{~cm}$ (Fig. 3).

Through this catheter we performed pulse-spray thrombolysis with alteplase. Firstly we injected a bolus dose of alteplase ( $2 \mathrm{mg}$ diffused in $5 \mathrm{ml}$ of saline), and then the drug was infused at a rate of $1 \mathrm{mg} / \mathrm{h}$. In addition, infusion of unfractionated heparin was continued through the side port of the sheath located in the popliteal vein. Adjustments of heparin dosages were made to maintain activated partial thromboplastin time (APTT) values within the range of 1.5 to 2.5 times the patient's baseline control. Local thrombolysis was continues for 72 hours, under monitoring of fibrinogen concentration and platelet counts. During thrombolytic therapy, tight compression bandaging was applied from the level of the foot up to the groin. Angiography performed $24 \mathrm{~h}$ and $48 \mathrm{~h}$ after the beginning of thrombolytic treatment revealed almost complete patency of the popliteal, femoral and iliac veins. On the $3^{\text {rd }}$ day of fibrinolysis an asymptomatic haematuria was observed, but ultrasound examination of the abdomen did not reveal abnormalities. On the same day we removed the Fountain catheter and through the popliteal access we introduced the 0.014" Eagle Eye Platinum Catheter (Volcano Corp., San Diego, CA, USA) and using the Volcano s5 Imaging System (Volcano Corp., San Diego, CA, USA) we performed intravascular ultrasound (IVUS) of the veins of the left lower extrem- ity. This examination revealed a compression of the left common iliac vein by the right common iliac artery (Fig. 4). After predilatation of the stenotic part of the vein with the $12 \times 40 \mathrm{~mm}$ Zelos balloon catheter (Optimed, Ettlingen, Germany), which was slowly inflated up to 12 atm (Fig. 5), endovascular treatment was completed with implantation of the $14 \times 60 \mathrm{~mm}$ Sinus-Obliquus hybrid venous stent (Optimed, Ettlingen, Germany) (Fig. 6). Angiography demonstrated a very good final result. The clinical result 3 days after stent implantation is presented in Fig. 7. Two days after the procedure the patient was mobilised and began an intensive rehabilitation programme. Haematuria was no longer present. We started anticoagulation with acenocoumarol (dose adjusted in accordance with the INR test) and antiplatelet therapy with clopidogrel (75 mg/day). The patient was advised to wear class 2 compression hosiery. Ten days after stent implantation the patient reported severe pain of the left lumbar region and iliac fossa. Abdominal bedside ultrasonography was suggestive of retroperitoneal bleeding. Therefore, abdominal CT was performed, which confirmed the presence of retroperitoneal haematoma. The patient was administered $5 \mathrm{mg}$ of vitamin $\mathrm{K}$, one unit of fresh frozen plasma and 2 units of blood. Then, she was transferred to the vascular surgery department. On the following day, when coagulation parameters returned to their normal values, the patient underwent surgical exploration, the haematoma was removed, but still the source of bleeding was not found. The patient was discharged in very good clinical condition, with the recommendation of anticoagulation therapy with acenocoumarol for at least 6 months. After 3 weeks, the filter implanted into the inferior vena cava was removed. The patient returned to full work activity.
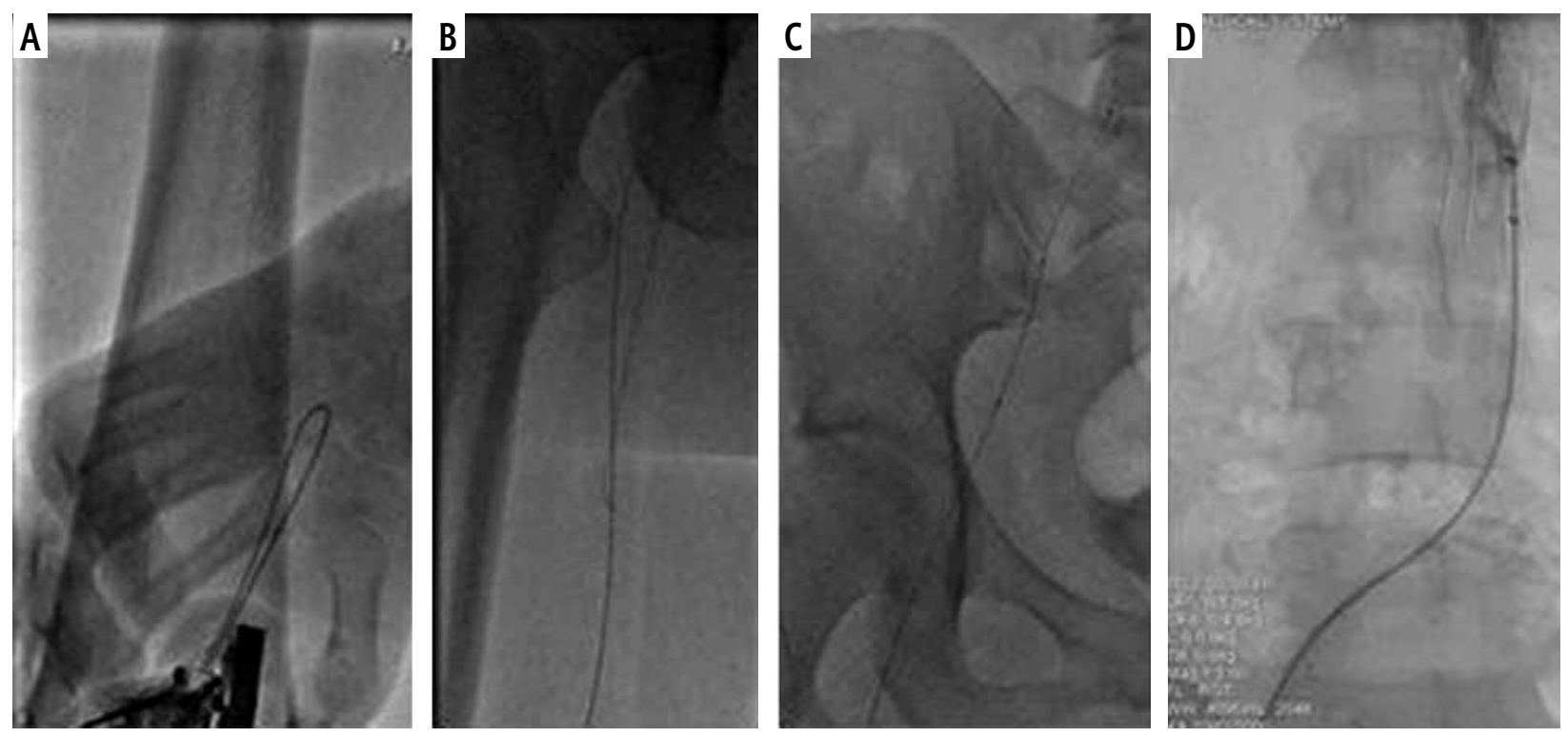

Fig. 3. Consecutive stages of the navigation through occluded femoral and iliac veins. A) puncture of the popliteal vein under ultrasound guidance; $\mathbf{B}$ and $\mathbf{C}$ ) navigation through occlusion with the Terumo guidewire; D) positioning of the Fountain thrombolysis catheter (its radiopaque end-tip is visible below the implanted IVC filter) 


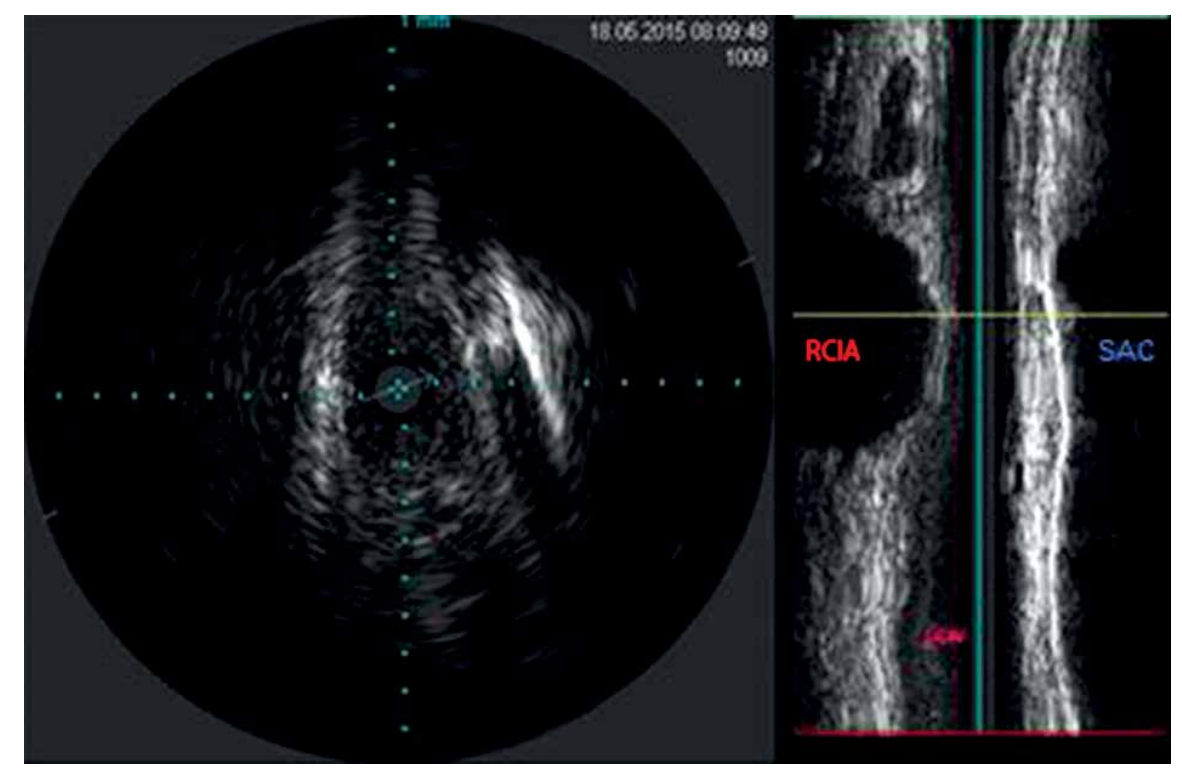

Fig. 4. Compression of the left common iliac vein (LCIV) by the right common iliac artery (RCIA) revealed by IVUS - a tight stenosis of the vein. On the left: cross-sectional view at the level of the yellow line on the right-sided picture. SAC: sacrum
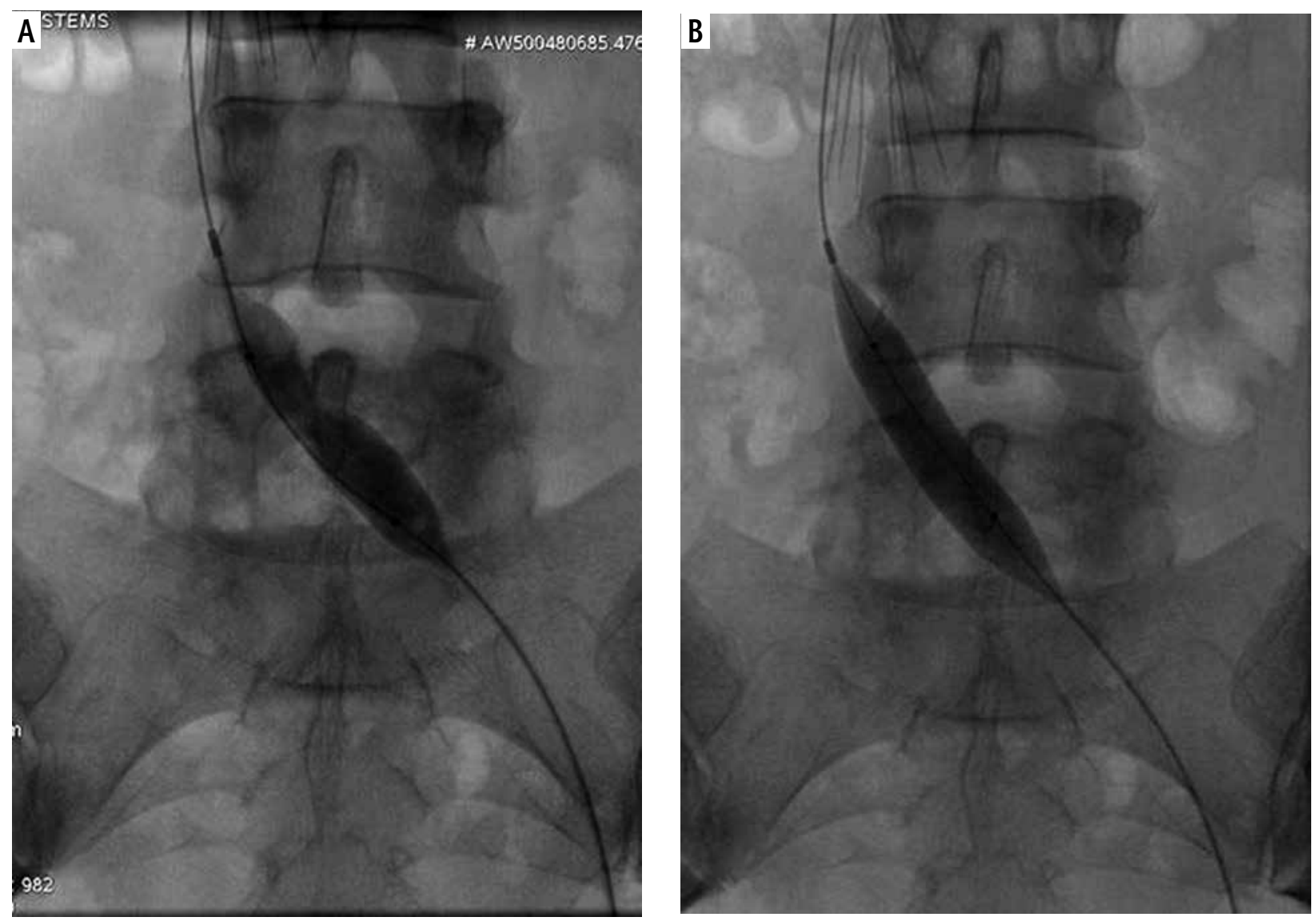

Fig. 5. Predilatation of stenosis of the common iliac vein stenosis with $12 \times 40 \mathrm{~mm}$ Zelos angioplastic balloon (Optimed). Modelling of the balloon on the lesion (A) and its final full expansion (B) 

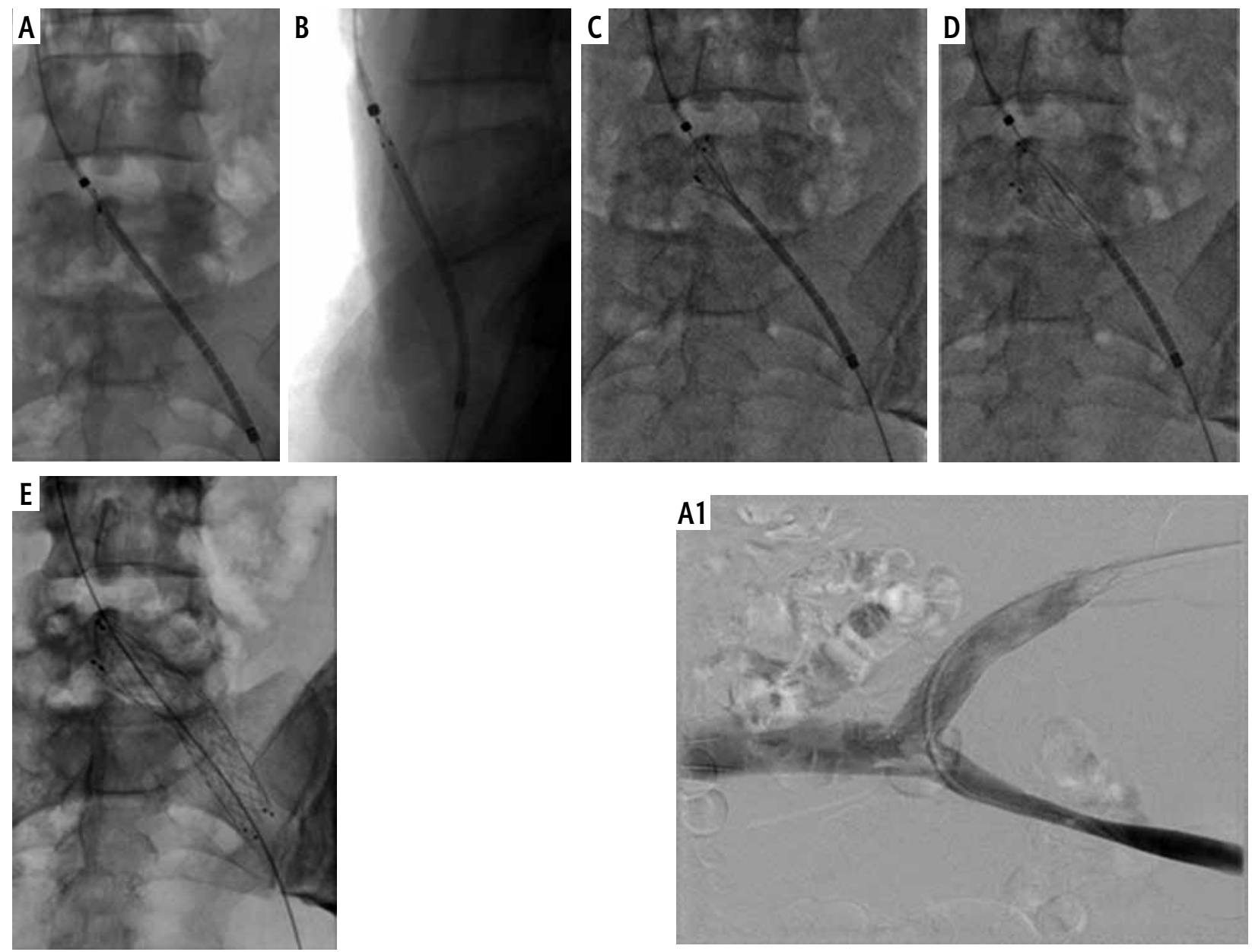

Fig. 6. Implantation of Sinus-Obliquus (Optimed) venous stent. Proper positioning of the stent directly at the bifurcation is facilitated by 4 radiopaque markers at the tip of the stent. In AP projection (first picture) two medial markers should overlap and in $90^{\circ}$ lateral projection (second picture) they should be symmetrically separated. During implantation firstly a stiffer closed-cell part of the stent is expanded (third and fourth pictures), and then the open-cell part of the stent is opened (fifth picture)

Fig. 6A1. Final venography of both iliac veins. The stent is fully expanded and there are residual thrombi in the proximal part of the right common iliac vein

\section{DISCUSSION}

The present case report deals with several aspects of the treatment for acute DVT of the pelvic, femoral and popliteal veins. According to the Polish Guidelines for Prevention and Treatment of Venous Thrombosis, published in 2012, catheter-directed thrombolytic therapy should be used in patients with a clinical history of DVT not longer than 14 days, in good general condition, with low risk of bleeding, and who consider the prevention of post-thrombotic syndrome as a priority $[7,8]$. However, the aforementioned therapy can also be effective in a case of DVT that is present for 21 [9] or even 28 days [10]. The present case confirms that catheter-directed thrombolysis can be effective even 14 days after onset of the disease.

There is an increased risk of recurrent DVT in a case of stenosis of the vein, and it has been found that a $40-50 \%$ reduction of the venous lumen can result in $70 \%$ higher risk of recurrent DVT [5]. Therefore, stent implantation seems to significantly affect the long-term efficacy of the thrombolytic therapy [11]. However, the choice of a proper stent remains problematic. At the moment there are four marketed stents that are registered for venous implantations. These are: Zilver Vena (Cook Medical Inc, Bloomington, IN, USA), Wallstent (Boston Scientific Corp., Marlborough, MA, USA), Vici (Veniti, Inc., St. Louis, MO, USA) and Sinus-Venous (Optimed, Ettlingen, Germany). These stents differ in the design, radial force, and flexibility. Therefore, they should be chosen individually in order to prevent complications and obtain an optimal effect in the long run.

In this patient we decided to implant one of the newest hybrid venous stents, named Sinus-Obliquus, manufactured by Optimed. The unique oblique design of the 
stent combines the advantages of a closed-cell stent (high radial force) and an open-cell device (high flexibility and plasticity), thus enabling its precise positioning and good clinical efficacy. In addition, it is not necessary to extend this stent into the inferior vena cava.

The decision regarding temporary implantation of an inferior vena cava filter is also controversial. In our patient we decided to implant the filter because she had already undergone PE, there was extension of the thrombus into the inferior vena cava, and the current thromboembolic event occurred despite anticoagulation with rivaroxaban. Also, in our opinion there was a risk of PE during endovascular manoeuvres aimed at recanalisation of femoral and iliac veins. Still, the guidelines do not recommend routine filter implantation in patients managed with anticoagulants (recommendation class 1B) [7, 8, 10-13].

The authors declare no conflict of interest.

\section{References}

1. White R.H. The epidemiology of venous thromboembolism. Circulation 2003; 107 (Suppl): 4-8.

2. Kahn S.R., Shrier I., Julian J.A., Ducruet T., Arsenault L., Miron M.J., Roussin A., Desmarais S., Joyal F., Kassis J., Solymoss S., Desjardins L., Lamping D.L., Johri M., Ginsberg J.S. Determinants and time course of the postthrombotic syndrome after acute deep venous thrombosis. Ann Intern Med 2008; 149: 698-707.

3. Wael I., Zakareya A.S., Hasan H., Wael A.Z. Endovascular management of May-Thurner syndrome. Ann Vasc Dis 2012; 5: 217-221.

4. Brazeau N.F., Harvey H.B., Pinto E.G., Deipolyi A., Hesketh R.L., Oklu R. May-Thurner syndrome: diagnosis and management. Vasa 2013; 42: 96-105.

5. O'Sullivan G.J., Semba C.P., Bittner C.A., Kee S.T., Razavi M.K., Sze D.Y., Dake M.D. Endovascular management of iliac vein compression (May-Thurner) syndrome. J Vasc Interv Radiol 2000; 11: 823-836.

6. Konstantinides S.V., Torbicki A., Agnelli G., Danchin N., Fitzmaurice D., Galiè N., Gibbs J.S., Huisman M.V., Humbert M., Kucher N., Lang I., Lankeit M., Lekakis J., Maack C., Mayer E., Meneveau N., Perrier A., Pruszczyk P., Rasmussen L.H., Schindler T.H., Svitil P., Vonk Noordegraaf A., Zamorano J.L., Zompatori M. Task Force for the Diagnosis and Management of Acute Pulmonary Embolism of the European Society of Cardiology (ESC). 2014 ESC guidelines on the diagnosis and management of acute pulmonary embolism. Eur Heart J 2014; 14: 3033-3069.

7. Zawilska K., Bała M., Błędowski P., Chmielewski D.W., Dobrowolski Z., Frączek M. Polskie wytyczne profilaktyki i leczenia żylnej choroby zakrzepowo-zatorowej - aktualizacja 2012. Med Prakt 2012; (Suppl): 48-50.

8. Kearon C., Akl E.A., Comerota A.J., Prandoni P., Bounameaux H., Goldhaber S.Z., Nelson M.E., Wells P.S., Gould M.K., Dentali F., Crowther M., Kahn S.R.; American College of Chest Physicians. Antithrombotic therapy for VTE disease: Antithrombotic Therapy and Prevention of Thrombosis, 9th ed: American College of Chest Physicians Evidence-Based Clinical Practice Guidelines. Chest 2012; 141 (Suppl): 419-494.
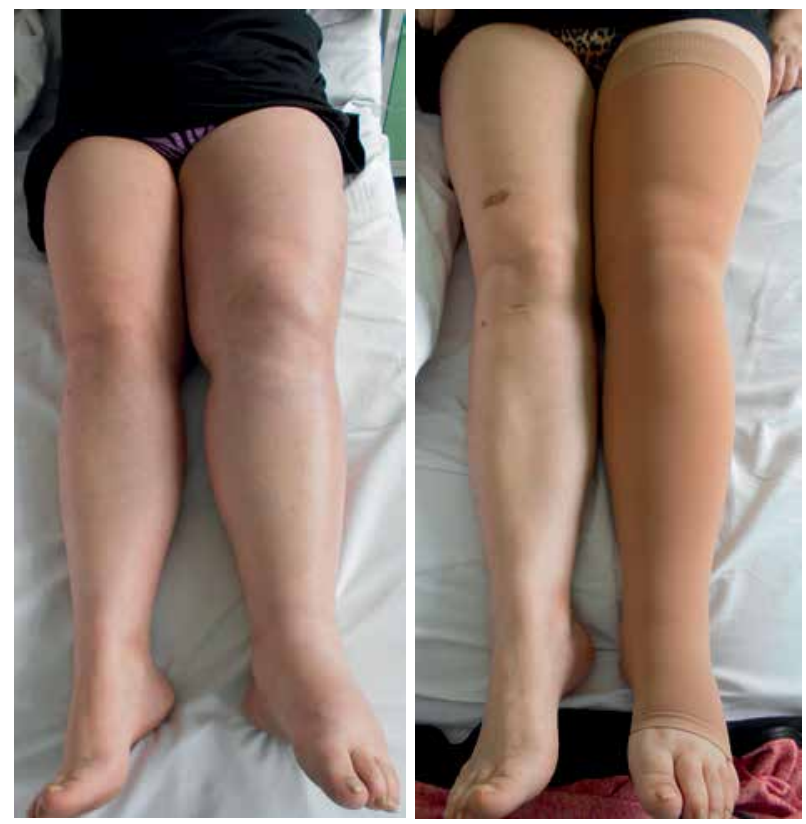

Fig. 7. Clinical result of the treatment: patient's legs on admission (left) and 3 days after stent implantation (right)

9. Enden T., Haig Y., Kløw N.E., Slagsvold C.E., Sandvik L., Ghanima W., Hafsahl G., Holme P.A., Holmen L.O., Njaastad A.M., Sandbæk G., Sandset P.M.; CaVenT StudyGroup. Long-term outcome after additional catheter-directed thrombolysis versus standard treatment for acute iliofemoral deep vein thrombosis (the CaVenT study): A randomised controlled trial. Lancet 2012; 379: 31-38.

10. Vedantham S., Sista A.K., Klein S.J., Nayak L., Razavi M.K., Kalva S.P., Saad W.E., Dariushnia S.R., Caplin D.M., Chao C.P., Ganguli S., Walker T.G., Nikolic B.; Society of Interventional Radiology and Cardiovascular and Interventional Radiological Society of Europe Standards of Practice Committees. Quality Improvement Guidelines for the Treatment of Lower-Extremity Deep Vein Thrombosis with Use of Endovascular Thrombus Removal. J Vasc Interv Radiol 2014; 25: 1317-1325.

11. Meissner M.H., Gloviczki P., Comerota A.J., Dalsing M.C., Eklof B.G., Gillespie D.L., Lohr J.M., McLafferty R.B., Murad M.H., Padberg F., Pappas P., Raffetto J.D., Wakefield T.W.; Society for Vascular Surgery; American Venous Forum. Early thrombus removal strategies for acute deep venous thrombosis: clinical practice guidelines of the Society for Vascular Surgery and the American Venous Forum. J Vasc Surg 2012; 55: 1449-1462.

12. Pollak A.M., McBane 2nd R.D. Succinct Review of the New VTE Prevention and Management Guidelines. Mayo Clin Proc 2014; 89: 394-408.

13. Sharifi M., Bay C., Skrocki L., Lawson D., Mazdeh S. Role of IVC filters inendovenous therapy for deep venous thrombosis: the FILTER-PEVI (filter implantation to lower thromboembolic risk in percutaneous endovenous intervention) trial. Cardiovasc Intervent Radiol 2012; 35: 1408-1413. 